\title{
OUTCOME OF PRIMARY REPAIR OF VESICOVAGINAL FISTULA (VVF)
}

Muhammad Khalida, Muhammad Hammad Hassan, Muhammad Asifc, Qadeer Ahmad Tariq ${ }^{\mathrm{d}}$ ${ }^{a}$ Associate Professor, Department of Urology, Dera Ghazi Khan Medical College, Dera Ghazi Khan. bSenior Registrar Department of Urology, Teaching Hospital/Dera Ghazi Khan Medical College, Dera Ghazi khan.

'Assistant Professor, Department of Urology, Dera Ghazi Khan Medical College, Dera Ghazi khan. dProfessor, Department of Urology, Sahiwal Medical College Sahiwal.

\section{ABSTRACT:}

BACKGROUND \& OBJECTIVE: Vesicovaginal fistula is one of the common gynecological problems faced by ladies in developing countries on account of certain significant lacunas in the healthcare delivery system and lack of awareness. The purpose of this study is to highlight our experience of primary vesicovaginal fistula repair.

METHODOLOGY: It is a cross-sectional experimental study from February 2019 to February 2020. Nineteen consecutive patients having vesicovaginal fistulas upto $3 \mathrm{~cm}$ in size, single in numberwere included in the study while those having fistulas more than $3 \mathrm{~cm}$, involving urethra, bladder neck, and ureteric orifice were excluded. After a detailed history, physical examination, laboratory workup, and cystoscopic examination under anesthesia, the fistulas were repaired. All information was noted on the pre-planned questionnaire for this purpose.

RESULTS: There are around $63 \%$ of patients having fistula infratrigonal and the rest percentage on the supratrigonal area of the urinary bladder. The risk factor found hysterectomy in $32 \%$ of patients, unsupervised home delivery in $16 \%$ of patients, C-Section in $12 \%$ of patients, delivery by an untrained person in $26 \%$ of patients, induced miscarriages in $5 \%$ of patients, and other risk factors found in $12 \%$ patients. The $68 \%$ of patients managed through transabdominal and the rest $32 \%$ patients operated through the transvaginal approach. The surgery, either transabdominal or transvaginal, was successfully done in $84 \%$ of patients and failed in the rest of $16 \%$ of patients.

CONCLUSION: Fistulas due to obstetric trauma were mostly preventable. The success of surgical repair was due to health professionals'expertise, the suitable decision about approach, method of repair, proper preoperative evaluation, and careful postoperative management.

KEYWORDS: Vesicovaginal, Fistula, Primary Repair, Miscarriages, Transabdominal, Transvaginal.

doi: https://doi.org/10.37723/jumdc.v12i4.436

\section{How to cite this:}

Khalid M, Hassan MH, Asif M, Tariq QA.OUTCOME OF PRIMARY REPAIR OF VESICOVAGINAL FISTULA (VVF). jumdc. 2020;12(2):146-151.

doi: https://doi.org/10.37723/jumdc.v12i2.436

This is an Open Access article distributed under the terms of the Creative Commons Attribution License (http://creativecommons.org/licenses/by/4.0), which permits unrestricted use, distribution, and reproduction in any medium provided the original work is properly cited. 


\section{INTRODUCTION:}

Vesicovaginal fistula (VVF) is an unusual passage between the urinary bladder and vaginal mucosa. In emergent nations, most cases $(>90 \%$ ) resulton account of prolonged obstructed labor ${ }^{[1]}$. Women who receive skilled obstetric care from expert professionals have less chances of getting this situation. Other causes of fistulas are iatrogenic (pelvic surgeries) ${ }^{[2,3]}$, sexual abuse(trauma) ${ }^{[4]}$, irradiation, and malignancy ${ }^{[5]}$. VVF exceptionally affects women's quality of life to such an extent that many of them develop behavioral changes like depression and unsociable manners.

The incidence of VVFin developing countries is reported as 124 per 100,000 deliveries $^{[6]}$. Insufficient skilled maternity centers, poverty, ignorance, and illiteracy are the main factors for this incidence. VVF may be categorized into two types, simple and complex. Simple small fistulas may be managed just by catheterization, having a satisfactory success rate of $2-30 \%{ }^{[7]}$. Surgery is a gold standard treatment, and principles of VVF repair remain the same,i.e., watertight, multilayered, tension-free, continuous bladder drainage, and uninfected repair regardless of the route ${ }^{[8]}$. Generally, success rate of VVF repair is variable in different studies and is around $98 \%$ in terms of cure at the first operation. The success rate of repair via vaginal route varies from 83$100 \%$ and from abdominal route $86-100 \%$, so the results are almost similar irrespective of the adopted route ${ }^{[9]}$.

Health is defined as a state of complete physical, mental, social wellbeing, and allcomponents of heath are extremely affected toa variable extent by fistula. Our study is planned to know the success rate of primary repair of VVF amongthe population of Dera Gazi Khan and suburb, resulting in great improvement in the quality of sufferer's life.

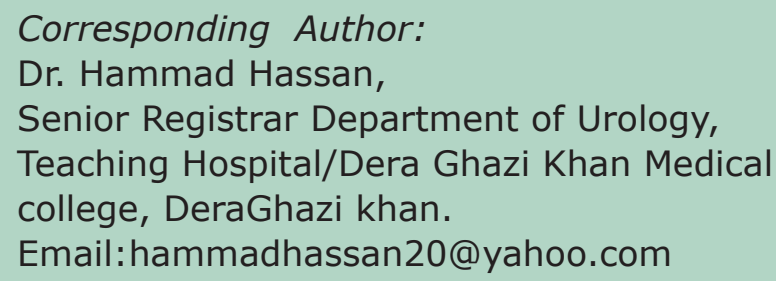

\section{METHODOLOGY:}

This Cross-sectional experimental study was conducted at the Department of Urology DHQ Teaching Hospital, Dera Ghazi Khan, from February 2019 to February2020. Nineteen cases with VVF were selected by a consecutive sampling technique. The patients with fistula more than $3 \mathrm{~cm}$ or fistula involving urethra, bladder neck, and ureteric orifice were excluded from the study. Chosen patients were evaluated regarding their age, parity, cause of fistula, place of delivery, and indication of pelvic surgery in case of obstetric fistula if it was a causative agent or any other cause involved. Cystoscopic examination under anesthesia was done to define its type, size, position, and condition of surrounding tissue, whether healthy or not. The surgery was done after fulfilling the preoperative pre-requisites. All particulars were recorded on predefined Performa.

Statistical Package for Social Sciences (SPSS) version 24 was used to analyze the data. Mean, and standard deviation was measured for quantitative variables and frequency distribution with percentage calculated for categorical variables. A pie chart was constructed for some graphical representation. Chi-Square and student t-test were applied to compare transabdominal with a transvaginal group.

The value of Cronbach 's AIpha is $40 \%$ which is describing that the questions recorded in this study- are clinically logical, relevant, and in sequence. 


\section{RESULTS:}

There are around $63 \%$ of patients having infratrigonal fistula and the rest (37\%) on supratrigonal area of the urinary bladder (Figure-I). The risk factor Hysterectomy found in 32\% of patients, Unsupervised Home Delivery in $16 \%$ patients, C-Section in $12 \%$ patients, Delivery by Untrained Person in $26 \%$ patients, Induced Miscarriages in 5\% patients and other risk factors found in $12 \%$ patients (Figure-II). There are $68 \%$ patients treated through Transabdominal surgery and rest $32 \%$ patients operated through Transvaginal surgery. The surgery either through transabdominal or transvaginal successfully done in $84 \%$ patients and failure was found in rest $16 \%$ patients.

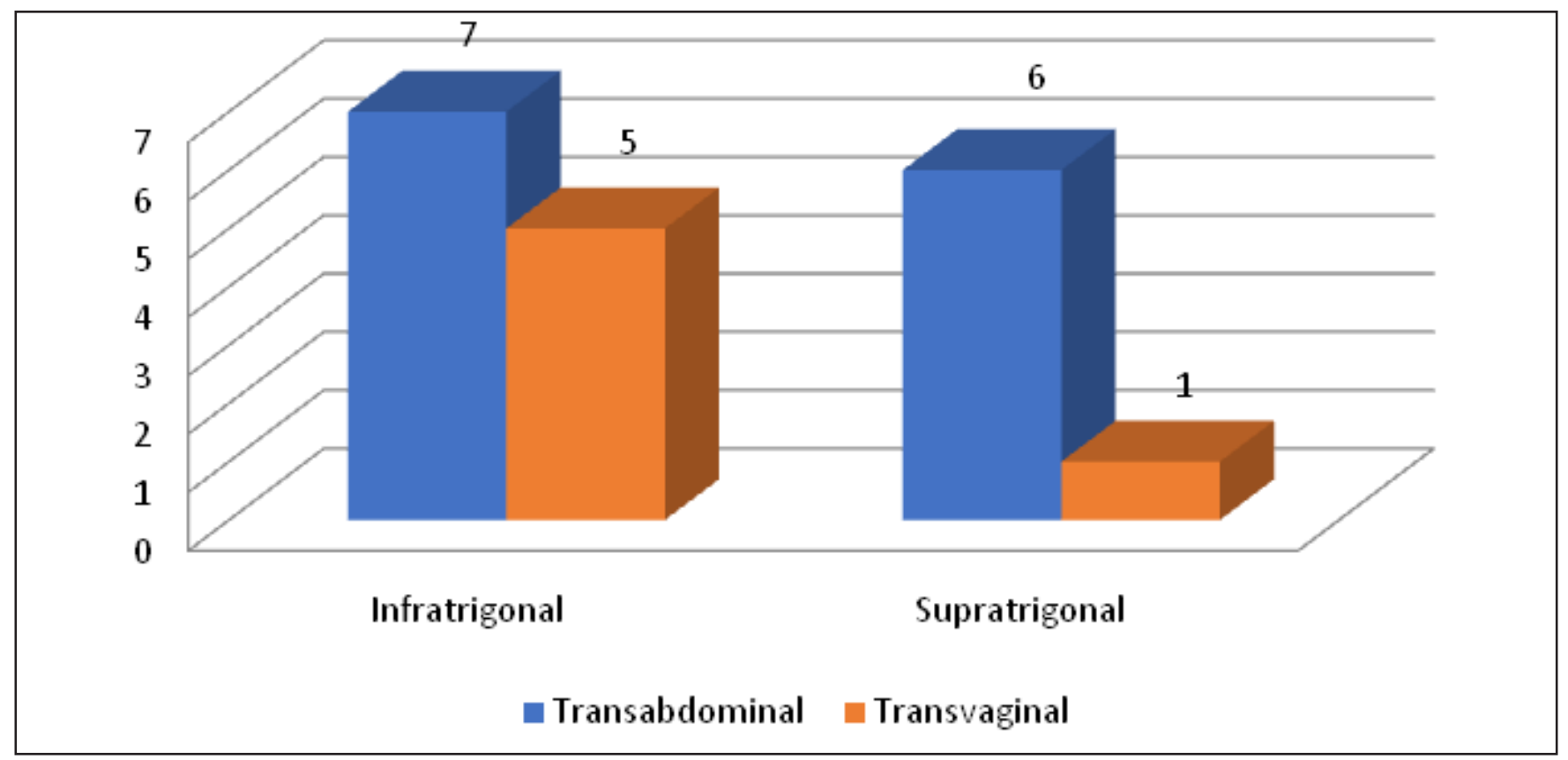

Figure-I: Site of fistula in study population.

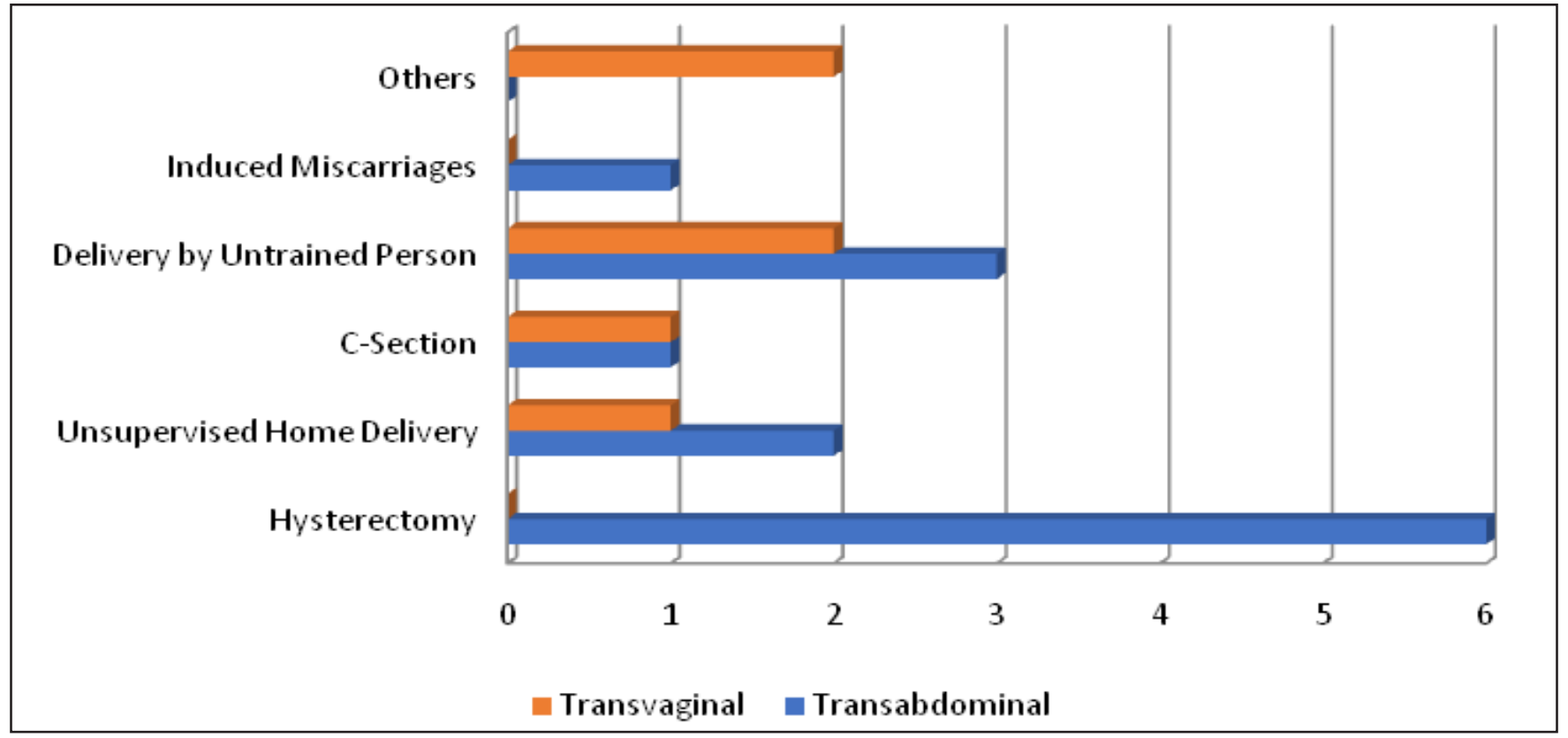

Figure-II: Risk factor for fistula development in study population. 
Table-I: Comparison between Transabdominal and Transvaginal routes of surgery on the base of Location of fistula using Chi-square test.

\begin{tabular}{|c|c|c|c|c|c|}
\hline & & & \multicolumn{2}{|c|}{ Routes of Surgery } & \multirow{2}{*}{ p-value } \\
\hline & & & Transabdominal & Transvaginal & \\
\hline \multirow{4}{*}{$\begin{array}{l}\text { Location of } \\
\text { Fistula }\end{array}$} & \multirow[t]{2}{*}{ Infratrigonal } & $\mathrm{N}$ & 7 & 5 & \multirow[t]{4}{*}{0.216} \\
\hline & & $\%$ & $36.8 \%$ & $26.3 \%$ & \\
\hline & \multirow[t]{2}{*}{ Supratrigonal } & $\mathrm{N}$ & 6 & 1 & \\
\hline & & $\%$ & $31.6 \%$ & $5.3 \%$ & \\
\hline \multirow{12}{*}{$\begin{array}{c}\text { Risk } \\
\text { Factors }\end{array}$} & \multirow[t]{2}{*}{ Hysterectomy } & $\mathrm{N}$ & 6 & 0 & \multirow[t]{12}{*}{0.154} \\
\hline & & $\%$ & $31.6 \%$ & $0.0 \%$ & \\
\hline & \multirow{2}{*}{$\begin{array}{l}\text { Unsupervised } \\
\text { Home Delivery }\end{array}$} & $\mathrm{N}$ & 2 & 1 & \\
\hline & & $\%$ & $10.5 \%$ & $5.3 \%$ & \\
\hline & \multirow[t]{2}{*}{ C-Section } & $\mathrm{N}$ & 1 & 1 & \\
\hline & & $\%$ & $5.3 \%$ & $5.3 \%$ & \\
\hline & \multirow{2}{*}{$\begin{array}{c}\text { Delivery by } \\
\text { Untrained Person }\end{array}$} & $\mathrm{N}$ & 3 & 2 & \\
\hline & & $\%$ & $15.8 \%$ & $10.5 \%$ & \\
\hline & \multirow{2}{*}{$\begin{array}{c}\text { Induced } \\
\text { Miscarriages }\end{array}$} & $\mathrm{N}$ & 1 & 0 & \\
\hline & & $\%$ & $5.3 \%$ & $0.0 \%$ & \\
\hline & \multirow[t]{2}{*}{ Others } & $\mathrm{N}$ & 0 & 2 & \\
\hline & & $\%$ & $0.0 \%$ & $10.5 \%$ & \\
\hline \multirow[t]{4}{*}{ Outcomes } & \multirow[t]{2}{*}{ Successful } & $\mathrm{N}$ & 11 & 5 & \multirow{4}{*}{0.943} \\
\hline & & $\%$ & $57.9 \%$ & $26.3 \%$ & \\
\hline & \multirow[t]{2}{*}{ Failed } & $\mathrm{N}$ & 2 & 1 & \\
\hline & & $\%$ & $10.5 \%$ & $5.3 \%$ & \\
\hline
\end{tabular}

The p-values are insignificant, which guided that fistula at Infratrigonal or Supratrigonal area may be repairedby using both transabdominal or transvaginal surgery whereas Hysterectomy, Unsupervised Home Delivery, C-Section, Delivery by Untrained Person, Induced Miscarriages and other any risk factor may be the cause of Vesicovaginal fistula. The p-value of outcome is also insignificant, which demonstrated that any surgery route may become successful or unluckily become a failure, but the highest percentage in both types of surgery is seen to be successful compared to failure.

Table-II: Comparison between Transabdominal and Transvaginal routes of surgery on the base of age and parity using independent sample t-test.

\begin{tabular}{|c|c|c|c|c|c|}
\hline Name of factor & $\begin{array}{c}\text { Routes of } \\
\text { Surgery }\end{array}$ & $\mathbf{N}$ & Mean & Std. Deviation & p-value \\
\hline \multirow{2}{*}{ Age } & Transabdominal & 13 & 30.92 & 2.660 & 0.565 \\
\cline { 2 - 5 } & Transvaginal & 6 & 30.00 & 4.195 & \multirow{2}{*}{0.358} \\
\hline \multirow{2}{*}{ Parity } & Transabdominal & 13 & 2.77 & 1.589 & \\
\cline { 2 - 5 } & Transvaginal & 6 & 2.00 & 1.789 & \\
\hline
\end{tabular}


Both p-values were found to be insignificant in between the transabdominal group and transvaginal group through age and parity, which describes that age or parity does not lead towards the route of transabdominal or transvaginal surgery among patients.

\section{DISCUSSION:}

Successful VVF repair depends on certain factors, including the location of fistula with relevance to the ureteric orifice, the patient's general health, accessibility from vagina and fistula type ${ }^{[10]}$. Most of the VVF due to obstetric causes are infratrigonal, resulting from impacted head and instrumental delivery. VVF repair via vaginal approach is the preferred technique because of cosmosis as no visible scar, less operative time, short hospital stays, and decreased blood loss [11]. Where the vaginal approach has limitation in case of small introitus, complex fistulas, supratrigonal fistulas, and previous failed vaginal repair ${ }^{[12]}$, their abdominal approach is appreciated. In many underdeveloped countries, vesicovaginal fistulas are mostly due to obstetric causes, but this situation doesn't exist in the western world due to their ideal antenatal and gynecological services $^{[13]}$. In our study, $52.64 \%$ of patients had obstetric fistulas, similar to some local and international studies [14]. The other study carried out at a tertiary care hospital of West Bengal where circumstances are almost like our country, vesicovaginal fistula in $66 \%$ of cases was depicted to be obstetric cause while in $34 \%$ of patients, gynecological causes like a complication of hysterectomy or after radiotherapy of tumor of cervix $^{[15]}$. Out of 10 patients in our study having obstetric fistulas, 3 were having home delivery, 5 were having delivery at some center by untrained personnel, and 2 were having $C$ section. This is in comparison to some of the studies cited above ${ }^{[9,12]}$. Our 9 patients out of $19(47.36 \%)$ had fistulas due to different gynecological procedures. The developed countries have $90 \%$ of fistulas due to iatrogenic injuries resulting from different pelvic surgeries ${ }^{[8]}$.

In our study, $63 \%$ of patients having trigonal or subtrigonal fistulas underwent transabdominal \& transvaginal repair. Transabdominal repair was done in $37 \%$ of patients with supratrigonal fistulas. In another study done in Ethiopia regarding characteristics and repair outcome of patients with vesicovaginal fistula, transvaginal repair was done in 161 patients out of 168 patients showed a success rate of $95.8 \%{ }^{[16]}$. In our study, 14 cases had successful surgery out of 19 cases which are $84.2 \%$. We are quite satisfied with this success rate as it is the firstever conducted study at this newly established teaching hospital. While the study conducted at a tertiary care hospital inWest Bengal Showing a success rate of $87.3 \%$, which is comparable to our study [17]. The study conducted at Muzaffarabad, Azad Kashmir, 24 cases out of 26 had successful primary repair, thus providing a success rate of $92.31 \%{ }^{[18]}$.

\section{CONCLUSION:}

Though most of the fistulas were preventable, the vesicovaginal fistula in our study could not be prevented due to lack of ideal health services. The present study suggests that primary VVF repair is a safe and efficacious treatment. Further improvement in fistula surgery is expected to be enhanced with the availability of skillful\& dedicated health professionals, adopting suitable repair techniques, providing vigilant preoperative assessment as well as careful postoperative management.

ACKNOWLEDGEMNET: None.

CONFLICT OF INTEREST: All authors disclose no conflict of interest.

\section{GRANT SUPPORT \& FINANCIAL DISCLOSURE: None}

\section{REFERENCES:}

1. Cortés RG, Clavijo R, Sotelo R. Laparoscopic treatment of genitourinary fistulae. Archives Espanoles Urologia. 2012;65(7):659-671.

2. Abu Gazala M, Wexner SD. Management of rectovaginal fistulas and patient outcome. Expert Review of Gastroenterology \& Hepatology. 2017;11(5):461-471. Doi:10.10 80/17474124.2017.1296355

3. Egziabher TG, Eugene N, Ben K, Fredrick K. Obstetric fistula management and predictors of successful closure among women attending a public tertiary hospital in Rwanda: a 
retrospective review of records. BioMed Central Research Notes. 2015;8(1):1-7. Doi:10.1186/s13104-015-1771-y

4. Rwihura OC, Mbangala B. Information Professionals' Role in Enhancing Awareness Creation towards Obstetric Fistula Treatment in Rural Areas of Tanzania. Library Philosophy \& Practice. 2017; 1490.

5. Langkilde NC, Pless TK, Lundbeck F, Nerstrom B. Surgical repair of vesicovaginal fistulae: a ten-year retrospective study. Scandinavian Journal of Urology and Nephrology. 1999;33(2):100-103.

6. Hilton $\mathrm{P}$, Cromwell DA. The risk of vesicovaginal and urethrovaginal fistula after hysterectomy performed in the English National Health Service-a retrospective cohort study examining patterns of care between 2000 and 2008. BJOG: An International Journal of Obstetrics \& Gynaecology. 2012;119(12):1447-1454.

7. Karshinia JA, Otubu JAM. Fistula In: Agboola A (Ed.) Textbook of obstetrics and gynaecology for medical students. Nigeria: Heinemann Educational; 2006:3951.

8. Borseth KF, Acharya G, Kiserud T, Trovik J. Incidence of gynecological fistula and its surgical treatment: A national registry-based study. Acta Obstetricia et Gynecologica Scandinavica. 2019;98(9):1120-1126.

9. Zhang Q, Ye Z, Liu F, Qi X, Shao C, He X, et al. Laparoscopic transabdominal transvesical repair of supratrigonal vesicovaginal fistula. International Urogynecology Journal. 2013;24(2):337-342.

10. Raashid Y, Majeed T, Majeed N, Shahzad N, Tayyab S, Jaffri $H$. Iatrogenic vesicovaginal fistula. Journal College of Physicians Surgeon Pakistan. 2010;20(7):436-438.

11. Rasool M, Tabassum SA, Mumtaz F. Vesicovaginal fistula repair: Urologist experience at Bahawalpur. Professional Medical Journal. 2006;13:445-452.

12. Lo TS, Chua S, Wijaya T, Kao CC, UyPatrimonio MC. Clinical relevance and treatment outcomes of vesicovaginal fistula (VVF) after obstetric and gynecologic surgery. Taiwanese Journal of Obstetrics and Gynecology. 2019;58(1):111-116. Doi:10.1016/j.tjog.2018.11.021

13. McKay E, Watts K, Abraham N. Abdominal approach to vesicovaginal fistula. Urologic Clinics. 2019;46(1):135-146. Doi: 10.1016/j. ucl.2018.08.011

14. Hilton P, Ward A. Epidemiological and surgical aspects of urogenital fistulae: a review of 25 years' experience in southeast Nigeria. International Urogynecology Journal. 1998;9(4):189-194.

15. Hilton P. Surgical fistula. In: Cardozo LD, Staskin D, editors. Textbook of female Urology and Urogynaecology. London: Taylor \& Francis; 2001:691710.

16. Datta B, Chattopadhyay S, Mandat M. Vesicovaginal fistula: Our experience of 47 cases in a tertiary care hospital of West Bengal. Journal of Evolution of Medical and Dental Sciences. 2016;5(47):2952-2955.

17. Sori DA, Azale AW, Gemeda DH. Characteristics and repair outcome of patients with Vesicovaginal fistula managed in Jimma University Teaching Hospital, Ethiopia. BMC Urology. 2016;16(1):41. Doi:0.1186/ s12894-016-0152-8

18. Shakil M, Ahmed R, Hanif S. Surgical Outcomes of Genitourinary Fistulae. Pakistan Journal of Physiology. 2016;12(4):30-32.

\section{Author's Contribution:}

Muhammad Khalid: Writing manuscript and study design.

Muhammad Hammad Hassan: Writing references, data analysis and framing of manuscript.

Muhammad Asif: Data collection and analysis. Qadeer Ahmad Tariq: Manuscript writing, data collection.

Submitted for publication: 07-07-2020

Accepted after revision: 06-02-2021 